\title{
The cholera outbreak in Yemen: lessons learned and way forward
}

\author{
Frederik Federspiel ${ }^{1 *}$ (D) and Mohammad $\mathrm{Ali}^{2}$
}

\begin{abstract}
The Yemen cholera outbreak has been driven by years of conflict and has now become the largest in epidemiologically recorded history with more than 1.2 million cases since the beginning of the outbreak in April, 2017. In this report we review and discuss the cholera management strategies applied by the major international humanitarian health organizations present in Yemen. We find the response by the organizations examined to have been more focused on case management than on outbreak prevention. Oral Cholera Vaccines (OCVs) were not delivered until nearly 16 months into the outbreak. A recent scale-up of the global OCV stockpile will hopefully allow for rapid mass deployment of the OCV in future humanitarian emergencies. Continuous funding to this stockpile will be crucial to maintain this option for prevention and control of cholera outbreaks. Of equal importance will be the timely recognition of the need for mass OCV deployment and development of more specific, comprehensive and actionable evidence-based frameworks to help guide this decision, however difficult this may be. The outbreak highlights the importance for international humanitarian health organizations to have a continuous discussion about whether and to what extent they should increase their focus on preemptively addressing the environmental determinants of communicable diseases in humanitarian emergencies. Strong advocacy from the public health community for peace and the protection of human health, by bringing to attention the public health impacts of armed conflict and keeping the world's political leaders accountable to their actions, will remain crucial.
\end{abstract}

Keywords: Cholera, Yemen, Conflict, Humanitarian response, Oral cholera vaccination, WaSH

\section{Background}

The United Nations have deemed the situation in Yemen the world's worst humanitarian crisis [1]. In the midst of this, the largest and fastest spreading cholera outbreak recorded since the WHO began recording cholera outbreaks in 1949 has erupted [2, 3]. As of October 7, 2018, the WHO estimates a cumulative total of 1,236,028 reported cases of cholera to have occurred in Yemen since the beginning of the outbreak in April, 2017 [4]. 2556 of these cases have been fatal, yielding a case fatality rate of $0.21 \%$ [4]. Children constitute $58 \%$ of reported cases [5].

How could an outbreak of this scale occur? Already before the conflict erupted, approximately half of all children under 5 were stunted reflecting a high prevalence of chronic malnutrition, lowering their resilience

\footnotetext{
* Correspondence: frederik.federspiel@lshtm.ac.uk

${ }^{1}$ Department of Global Health and Development, London School of Hygiene

\& Tropical Medicine, 9 Tavistock Place, London WC1H 9SH, UK

Full list of author information is available at the end of the article
}

towards cholera [6, 7]. Water, Sanitation and Hygiene (WaSH) infrastructure was limited [8]. Destruction of the fragile $\mathrm{WaSH}$ bulwark against water-borne disease started when bombings commenced in March, 2015 [9]. Over the past 3 years, key infrastructure in Yemen has been destroyed, hampering the possibility of prevention and control of cholera in the country. The main seaport to Yemen, Al-Hudeydah, has been bombed and later blocked, disrupting the supply of aid and other supplies into the country $[10,11]$. The bridge that used to serve as the main supply route to the capital, Sana'a, has been bombed and so have hospitals and other medical facilities [3, 9, 12-14]. The United Nations Office for the Coordination of Humanitarian Affairs (UNOCHA) have estimated that "16 million [people] lack access to safe water and sanitation, and 16.4 million lack access to adequate healthcare" [15]. The costs of food, water, fuel, medicines and other basic commodities have increased

(c) The Author(s). 2018 Open Access This article is distributed under the terms of the Creative Commons Attribution 4.0 International License (http://creativecommons.org/licenses/by/4.0/), which permits unrestricted use, distribution, and reproduction in any medium, provided you give appropriate credit to the original author(s) and the source, provide a link to the Creative Commons license, and indicate if changes were made. The Creative Commons Public Domain Dedication waiver (http://creativecommons.org/publicdomain/zero/1.0/) applies to the data made available in this article, unless otherwise stated. 
dramatically [16-18], lowering overall resilience towards cholera in Yemen even further.

It is clear that such a collapse of infrastructure has created fertile ground for a cholera outbreak, and that the critical triggering cause was conflict [9, 15, 17, 19-22]. Both this cause of the problem and its ultimate solution lie in the political realm, and we strongly advocate for immediate political resolution with involvement from a so far neglectful international community [23-25]. However, cholera outbreaks frequently occur on the backdrop of conflict and/or poor WaSH infrastructure yet fail to spread so rapidly or to reach this magnitude [26-30]. In this debate piece we wish to examine if there are any lessons for the humanitarian and public health community that can be taken away from the humanitarian response in Yemen to better equip us to do our part in preventing future outbreaks from reaching this scale.

We reviewed publicly available information on the official websites and in reports from the major international health organizations involved in the humanitarian response in Yemen in December 2017, and academic English language literature on the Medline, Embase and Global Health databases published from 2015 and onward until submission in May 2018 (search string: "Yemen AND cholera"), to inform a discussion of potential shortcomings and lessons to be learned from the humanitarian response by health organizations. Our academic literature search yielded 40 results, the relevant of which are included in this paper. Our review findings are summarized in Table 1.

\section{Main text}

International humanitarian health organization responses and funding shortfalls

The Yemen Health Cluster consists of 40 member organizations and is coordinated by the WHO [31]. In June, 2017, the WHO and the Health and Water Sanitation and Hygiene (WaSH) Clusters in Yemen published a response plan for the cholera outbreak [32]. The plan included two principal approaches to cholera management: a) treating all cases of Acute Watery Diarrhea (AWD) as cholera without the need for lab confirmation in areas where cholera has been previously culture confirmed, and b) early response epidemiological and case management activities when a suspected case is reported in an outbreak-free area. These actors also reported planning to explore the feasibility of an Oral Cholera Vaccination (OCV) campaign [32].

As part of their general response in Yemen, the WHO described having sustained functionality of 414 health facilities, operation of 406 general health and nutrition mobile teams and delivery of child and nutrition interventions in 323 districts, having established 36 cholera treatment centers, expanded disease surveillance capacity and having distributed more than 2 million liters of fuel for hospital generators, ambulances etc. [33]. Specifically, the WHO reported having established 139 oral rehydration corners, trained 900 health workers in the management of cholera, delivered 1 million bags of IV fluids, distributed 158 cholera kits and sent 1450 cholera cots [34], and they had shipped in ambulances as well [22]. Through these and other interventions the WHO described having treated 700,000 suspected cases of cholera [34].

UNICEF described having provided safe water to over one million people and delivered 40 tons of medical equipment including medicine, Oral Rehydration Solution (ORS), IV fluids and diarrhea kits [35]. UNICEF serves as the WaSH cluster lead and reported having run several cholera awareness campaigns including the deployment of 20,000 community hygiene promoters $[35,36]$.

On their webpage for Yemen, the International Rescue Committee (IRC) described delivering health, nutrition, WaSH services, essential drugs and medical supplies, training health staff on cholera treatment and advocating for a direct humanitarian air service and for peace [37]. In a Lancet appeal, IRC staff further described providing seven hospitals with drugs, supplies and infrastructure, deploying mobile health teams and establishing community health volunteer networks for referral of malnourished children to treatment and counsel [38].

The International Committee of the Red Cross (ICRC) reported having sent medical supplies including IV fluids, ORS, antibiotics and chlorine tablets for cholera management, supported 17 cholera treatment facilities and provided care to nearly one in five cholera cases in Yemen, and they had dispatched engineers to restore water supply systems in the country [22,39].

Médecins Sans Frontières (MSF) described having admitted more than 103,000 patients to 37 cholera treatment centers and oral rehydration points [40] and planning to conduct outreach activities including chlorination of infected water sources, distribution of hygiene kits and awareness-raising via radio stations and mosques [41].

While the above is not an exhaustive list of all the activities of these organizations, it should at least provide an overview of some of their main focus areas in Yemen up until the time of review. It is also important to note that it was not within the scope of this paper to review the activities of all major engineering and infrastructure organizations present in Yemen, as well as the examined health organizations, and the following discussion of sanitation efforts will pertain only to organizations with a health mandate. Furthermore, the humanitarian crisis in Yemen has been neglected by the international community [23-25], and any criticism of the humanitarian response presented in this paper should reflect back to other stakeholders such as donors, politicians and other 
Table 1 Summary of some of the key activities of the major international humanitarian health organizations in Yemen as stated on their official websites in December, 2017, and in the academic literature reviewed by May, 2018. This is not an exhaustive list, but may serve as an indicator of some of the main focus areas of these individual organizations during the conflict up until the reviews were conducted. (Some categories may overlap)

\begin{tabular}{|c|c|c|c|c|c|}
\hline Key activities & $\mathrm{WHO}[22,31,33,34]$ & UNICEF $[35,36]$ & $\operatorname{IRC}[37,38]$ & ICRC $[22,39]$ & $\operatorname{MSF}[40,41]$ \\
\hline \multirow[t]{4}{*}{$\begin{array}{l}\text { Delivery of new } \\
\text { health services }\end{array}$} & $\begin{array}{l}\text { Operated } 406 \\
\text { general health and } \\
\text { nutrition mobile } \\
\text { teams }\end{array}$ & & $\begin{array}{l}\text { Delivered health and } \\
\text { nutrition services, essential } \\
\text { drugs and medical supplies }\end{array}$ & & $\begin{array}{l}\text { Established } 37 \text { cholera } \\
\text { treatment centers and oral } \\
\text { rehydration points }\end{array}$ \\
\hline & $\begin{array}{l}\text { Delivered child and } \\
\text { nutrition interventions } \\
\text { in } 323 \text { districts }\end{array}$ & & $\begin{array}{l}\text { Deployed mobile health } \\
\text { teams }\end{array}$ & & \\
\hline & $\begin{array}{l}\text { Established } 36 \text { cholera } \\
\text { treatment centers }\end{array}$ & & $\begin{array}{l}\text { Established community } \\
\text { health volunteer networks } \\
\text { for referral of malnourished } \\
\text { children to treatment and } \\
\text { counsel }\end{array}$ & & \\
\hline & $\begin{array}{l}\text { Established } 139 \text { oral } \\
\text { rehydration corners }\end{array}$ & & & & \\
\hline $\begin{array}{l}\text { Support of } \\
\text { existing } \\
\text { health system }\end{array}$ & $\begin{array}{l}\text { Sustained functionality } \\
\text { of } 414 \text { health facilities }\end{array}$ & & See "Health infrastructure" & $\begin{array}{l}\text { Supported } 17 \text { cholera } \\
\text { treatment facilities }\end{array}$ & \\
\hline \multirow[t]{5}{*}{$\begin{array}{l}\text { Health } \\
\text { infrastructure }\end{array}$} & $\begin{array}{l}\text { Distributed more than } \\
2 \text { million liters of fuel } \\
\text { for hospital generators, } \\
\text { ambulances etc. }\end{array}$ & $\begin{array}{l}\text { Delivered } 40 \text { tons of } \\
\text { medical equipment } \\
\text { including medicine, } \\
\text { ORS, IV fluids and } \\
\text { diarrhea kits. }\end{array}$ & $\begin{array}{l}\text { Provided seven hospitals } \\
\text { with drugs, supplies and } \\
\text { infrastructure }\end{array}$ & $\begin{array}{l}\text { Sent medical supplies } \\
\text { including IV fluids, ORS, } \\
\text { antibiotics and chlorine } \\
\text { tablets for cholera } \\
\text { management }\end{array}$ & \\
\hline & $\begin{array}{l}\text { Delivered } 1 \text { million } \\
\text { bags of IV fluids }\end{array}$ & & & & \\
\hline & $\begin{array}{l}\text { Distributed } 158 \\
\text { cholera kits }\end{array}$ & & & & \\
\hline & Sent 1450 cholera cots & & & & \\
\hline & $\begin{array}{l}\text { Shipped in } \\
\text { ambulances }\end{array}$ & & & & \\
\hline \multirow[t]{2}{*}{ WaSH } & & $\begin{array}{l}\text { Provided safe water } \\
\text { to over one million } \\
\text { people }\end{array}$ & Delivered WaSH services & $\begin{array}{l}\text { Dispatched engineers to } \\
\text { restore water supply } \\
\text { systems in the country }\end{array}$ & $\begin{array}{l}\text { Planned to conduct } \\
\text { outreach activities } \\
\text { including chlorination } \\
\text { of infected water sources } \\
\text { and distribution of } \\
\text { hygiene kits }\end{array}$ \\
\hline & & $\begin{array}{l}\text { Deployed 20,000 } \\
\text { community hygiene } \\
\text { promoters (part of } \\
\text { awareness campaigns } \\
\text { below) }\end{array}$ & & & \\
\hline Staff training & $\begin{array}{l}\text { Trained } 900 \text { health } \\
\text { workers in cholera } \\
\text { management }\end{array}$ & & $\begin{array}{l}\text { Trained health staff on } \\
\text { cholera treatment }\end{array}$ & & \\
\hline $\begin{array}{l}\text { Epidemiological } \\
\text { activities }\end{array}$ & $\begin{array}{l}\text { Expanded disease } \\
\text { surveillance capacity }\end{array}$ & & & & \\
\hline Management & $\begin{array}{l}\text { Coordination of Health } \\
\text { Cluster Yemen }\end{array}$ & WaSH cluster lead & & & \\
\hline Awareness & & $\begin{array}{l}\text { Ran several cholera } \\
\text { awareness campaigns }\end{array}$ & & & $\begin{array}{l}\text { Planned to conduct } \\
\text { awareness-raising via radio } \\
\text { stations and mosques }\end{array}$ \\
\hline Advocacy & & & $\begin{array}{l}\text { Advocated for a direct } \\
\text { humanitarian air service } \\
\text { and for peace }\end{array}$ & & \\
\hline $\begin{array}{l}\text { Summary output of } \\
\text { activities }\end{array}$ & $\begin{array}{l}\text { Treated } 700,000 \\
\text { suspected cases } \\
\text { of cholera }\end{array}$ & & & $\begin{array}{l}\text { Provided care to nearly } \\
\text { one in five cholera } \\
\text { cases in Yemen }\end{array}$ & $\begin{array}{l}\text { Admitted more than } \\
103,000 \text { patients }\end{array}$ \\
\hline
\end{tabular}


decision makers that have failed to allocate sufficient resources to this crisis. In regards hereto, the IRC has pointed to the fact that "only $47 \%$ of the UN's 2016 response plan was funded, leaving a shortfall of US\$868 million to cover the basic needs of 14 million people" [38], while the WHO experienced a funding gap of more than $80 \%$ in late 2015 for their activities in the Yemen health cluster [42, 43]. At the High-Level Pledging Event for the Humanitarian Crisis in Yemen on April 25, 2017 in Geneva, US\$1.1 billion was raised, falling short US\$1 billion from the UN estimate of what would be needed "to prevent a full-blown humanitarian catastrophe in Yemen" [22]. An additional funding appeal at the event for $\$ 250$ million specifically for combatting cholera yielded only \$47 million [22]. This was eventually followed up by a US\$2 billion funding pledge at a new High-Level Pledging Event in April, 2018, with financial contributions among others coming from Saudi Arabia, the United Arab Emirates and Kuwait, which are member countries of the Saudi-led coalition, and the United States, the United Kingdom and France, which are supporting countries [44-50].

\section{Oral cholera vaccines}

A striking observation from our review of the humanitarian response is the absence of delivering OCVs in any of the examined organizations' attempts to control the outbreak, except for the WHO, Health and WaSH clusters' description of plans to explore the feasibility of OCVs. At the time (December, 2017), nearly 1 million cases had already occurred [51]. In July 2017, 3 months into the outbreak, 500,000 OCVs had been scheduled to arrive in Sana'a, but they were redirected because the request was cancelled by the requestor [52]. A concern raised by some aid agencies was that a mass immunization would be logistically difficult and that the impact of vaccination would be minimal due to the scale of the outbreak [53]. In a Lancet Gastroenterology \& Hepatology editorial it is stated that "... plans for a vaccination effort were deemed futile and scrapped, citing security issues, challenges in distribution and administration, and the sheer scale of the epidemic..." [22]. In August 2018, nearly 16 months into the outbreak, OCVs were finally delivered to 540,000 people by the WHO and UNICEF, and a follow-up round was conducted in September reaching about 387,000 of these people $[54,55]$.

OCVs for emergency settings are stored in a donorfunded stockpile managed by the International Coordinating Group on Vaccine Provision (ICG) [5]. A recent metaanalysis of seven randomized trials and six observational studies estimates the mean effectiveness of standard twodose killed oral cholera vaccination at $76 \%$ and mean efficacy at $58 \%$, with protection lasting for at least 3 years [56]. Oral cholera vaccination has been demonstrated to be safe, logistically feasible and acceptable by the recipient population [56-60], as well as inexpensive in various settings, with total costs including procurement and delivery per fully vaccinated individual of less than US\$10 [61-65].

Accepting the unacceptable premise that the Yemeni conflict became reality, the question that arises is: Could the largest cholera outbreak ever recorded have been avoided or at least managed, had enough OCVs been deployed earlier on in the conflict?

The solely theoretically based answer to this question is: Most likely, given the available evidence of the qualities of OCVs. However, considering the nature of this humanitarian emergency, this answer becomes little more than an ex post facto rationalization of a deeply chaotic situation that, as indicated above, most probably did not lend itself to orderly and comprehensive public health interventions such as mass vaccination.

Human Rights Watch have reported utterly chaotic conditions in Yemen [66]. If their reports are anywhere close to the truth, then that would provide an explanation of why mass OCV campaigns may simply not have been possible earlier on in the conflict, as indicated by the Lancet Gastroenterology \& Hepatology editorial mentioned earlier [22]. Also, given the fact that more than two million Yemenis are internally displaced within their country [67], and that many likely are internally trapped, mass public health interventions are nowhere as easily carried out as in a refugee camp setting in a country not immersed in conflict.

However, this explanation is challenged by the magnitude of the other humanitarian operations that it evidently has been possible to carry out in Yemen. In light hereof, some level of criticism may be warranted of the international humanitarian response as being very adept at managing cases when the outbreak had begun, as reflected by the impressively low case fatality rate of $0.21 \%$, but ill-equipped in terms of preventing a cholera outbreak in the approximately 2 years of conflict and humanitarian presence that preceded the outbreak (this view is shared by Dr. Anita Zaidi in a recent opinion piece in Nature [68]), or controlling it once it had occurred.

\section{Moving forward}

Concerning water and hygiene interventions, it appears that the Health and WaSH clusters, the IRC, MSF and ICRC have been thoroughly engaged. However, we were unable to document any major dedicated sanitation interventions carried out by the international humanitarian health organizations investigated. As mentioned, this may likely be due to the type of organizations examined, but nevertheless it leads to the question of whether and to what extent international humanitarian health organizations should increase their focus on addressing the environmental determinants of health rather than managing the cases they generate. This is a core discussion in 
humanitarian health that it is not within our mandate nor our abilities to answer, but the case of Yemen underlines the necessity of having this discussion on a continuous basis within each implementing humanitarian health organization. Going forward, given the current breakdown of sanitation systems [15] and the key importance of sanitation for prevention of a cholera outbreak in areas where the population has not been exposed and has no immunity to cholera, as well as for prevention of other waterborne disease outbreaks, sanitation has to be a key priority in the ongoing humanitarian response and the future development work when the conflict settles.

OCVs were not delivered until nearly 3.5 years into this humanitarian emergency, which has most likely been due to ongoing conflict, logistical circumstances, the scale of the epidemic, impairment of the humanitarian response by the parts to the conflict and some degree of negligence from donors, politicians and other decision makers. Whatever the reasons, OCVs were not distributed until nearly 16 months into the cholera outbreak by which time more than a million cases had accumulated. Neither were they in the two years of WaSH infrastructure breakdown that preceded the outbreak. This should serve as a historic example of the failure to control the spread of cholera given the tools that are available. Today, "cholera outbreaks are entirely containable" (The Lancet editorial, 2017) [6].

Based on their experience with the cholera outbreak in Juba, South Sudan, Parker et al. (2017) advocate among other things for improved laboratory and surveillance capacity in countries to be able to declare outbreaks faster, and for simplification of the mechanisms to access the ICG stockpile to allow for timely deployment of vaccines [69].

Single-dose killed oral cholera vaccination has been attempted, and the strategy has shown a mean shortterm effectiveness of $69 \%$ in meta-analysis based on two studies [56], and 40\% efficacy based on one trial [70]. This could serve as a potential option for when logistical and security constraints render the standard regimen impossible [56, 60, 69-71]. The strategy however remains contended $[72,73]$ and needs further evaluation. Live-attenuated OCVs have been developed and shown promising results for single-dose administration [74], however their cost is likely going to be a significant barrier to their use in mass vaccination campaigns.

The 2011 Sphere Handbook applicable in the Yemen conflict did not specifically recommend reactive or preemptive mass OCVs [75], but it was also written before the advent of the ICG OCV stockpile. The available draft of the upcoming 2018 version includes this, and we warmly welcome this progress [76]. The ICG stockpile has now expanded from 2 million doses entering the stockpile per year in 2013 to over 25 million doses expected annually from 2018 and onwards [77]. This scale-up will be a crucial improvement of the ability to control cholera in emergency settings, and sustained funding to maintain this stockpile will be essential for controlling future outbreaks.

Assessment of the need for mass OCVs should happen pre-emptively in a humanitarian emergency. Regarding this issue, Qadri et al. (2017) and Parker et al. (2017) argue for the development of validated predictive tools to help guide the decision on when and to which humanitarian emergencies OCVs should be deployed, a notion we do support, whilst acknowledging the difficulty of the task of predicting the outbreak of cholera $[53,69]$. The current WHO framework for decision-making on vaccination in acute humanitarian emergencies offers a tool for assessing the risk level for a cholera outbreak, and in the case of Yemen, the high-risk criteria were fulfilled [78]. The current WHO position paper on cholera vaccines offers general advice in four sentences on which factors to consider regarding the use of OCVs for cholera control in humanitarian emergencies [79], while the available draft of the 2018 Sphere Handbook offers further general advice on this [76]. In the end, the decision has to be made on a case-by-case basis by the people involved in a given humanitarian response, leaving room for a degree of arbitrary in the decision-making process that should at least be sought to be minimized through the development of more specific, comprehensive and actionable frameworks based on the accumulating and promising evidence from mass $\mathrm{OCV}$ campaigns in humanitarian emergencies [26, 29, 60, 71, 80-84].

Based on the example of Yemen, Dureab et al. (2017) argue for the institution of emergency preparedness systems by countries in conflict capable of preventing epidemics [21]. While we do applaud this thought as viewed in isolation, we see considerable political, institutional and logistical barriers to such systems during active conflict, and believe that part of this mandate therefore necessarily has to remain in the hands of international impartial institutions such as the UN organizations.

Finally, in terms of advocacy, The Lancet editorial board notes that high-level attention for Yemen is necessary with continued advocacy including at the UN level for the protection of health in conflict situations [25]. We will add that public health professionals and -academics are in a strong position to join in by applying their knowledge and skills in advocacy efforts for peace and the preservation of public health in conflict and to keep the world's leaders accountable for the health and human rights consequences of their actions.

\section{Conclusions}

The conflict in Yemen has caused the largest cholera outbreak in epidemiologically recorded history. OCVs were not delivered pre-emptively, nor until nearly 16 
months into the outbreak, during which time more than a million cases occurred. We are, hopefully, entering into a new era in which OCVs will be amply available for rapid disbursement to humanitarian emergencies. Continuous funding to the ICG OCV stockpile will be crucial to maintain this option for prevention and control of cholera outbreaks. Of equal importance will be the timely recognition of the need for mass OCV deployment and development of more specific, comprehensive and actionable evidencebased frameworks to help guide this decision, however difficult this may be. The Yemen cholera outbreak highlights the importance for international humanitarian health organizations to have a continuous discussion about whether and to what extent they should increase their focus on pre-emptively addressing the environmental determinants of communicable diseases in humanitarian emergencies. Finally, strong advocacy from the public health community for peace and the protection of human health, by bringing to attention the public health impacts of armed conflict and keeping the world's political leaders accountable to their actions, will remain crucial.

\section{Abbreviations}

AWD: Acute Watery Diarrhea; ICG: International Coordinating Group on Vaccine Provision; ICRC: International Committee of the Red Cross; IRC: International Rescue Committee; MSF: Médecins Sans Frontières; OCVs: Oral Cholera Vaccines; ORS: Oral Rehydration Solution; UNICEF: United Nations Children's Fund; UNOCHA: United Nations Office for the Coordination of Humanitarian Affairs; WaSH: Water, Sanitation and Hygiene; WFP: World Food Programme; WHO: World Health Organization

\section{Acknowledgements}

Not applicable.

\section{Funding}

Financial support for preparation of the manuscript was provided by the Delivering Oral Vaccine Effectively (DOVE) project. DOVE is supported by the Bill and Melinda Gates Foundation (Grant number OPP1148763) and administered through the Johns Hopkins Bloomberg School of Public Health. The funder had no role in preparation of the manuscript and decision to publish it.

\section{Availability of data and materials}

Data sharing is not applicable to this article as no datasets were generated or analyzed during the current study.

\section{Authors' contributions}

FF conceived the paper, conducted the review and wrote the first draft of the manuscript. FF and MA discussed the findings and their interpretation and edited the manuscript together. Both authors read and approved the final manuscript.

\footnotetext{
Authors' information

Dr. Frederik Federspiel, MD, MPH, is a PhD Candidate in Public Health and Policy at the London School of Hygiene \& Tropical Medicine. He conducted research on cholera under the supervision of Dr's Mohammad Ali and David Sack during his MPH studies at the Johns Hopkins Bloomberg School of Public Health. Dr. Mohammad Ali, MA, PhD, is a Senior Scientist at the Dept. of International Health at the Johns Hopkins Bloomberg School of Public Health. Dr. Ali is the author and co-author of more than 60 publications on cholera and is a senior member of the Delivering Oral Vaccine Effectively (DOVE) Project.
}

Ethics approval and consent to participate

Not applicable.

\section{Consent for publication}

Not applicable.

Competing interests

The authors declare that they have no competing interests.

\section{Publisher's Note}

Springer Nature remains neutral with regard to jurisdictional claims in published maps and institutional affiliations.

\section{Author details}

'Department of Global Health and Development, London School of Hygiene \& Tropical Medicine, 9 Tavistock Place, London WC1H 9SH, UK. ${ }^{2}$ Department of International Health, Johns Hopkins Bloomberg School of Public Health, 615 N. Wolfe Street, Baltimore, MD 21205, USA.

Received: 14 May 2018 Accepted: 19 November 2018

Published online: 04 December 2018

References

1. UN News. Yemen 2018 [Available from: https://news.un.org/en/focus/ yemen. Last Accessed 2018 Apr 26].

2. Save the Children. Yemen: Cholera Outbreak now Largest and Fastest on Record, 600,000 Children Infected by Christmas 2017 [Available from: https://www.savethechildren.net/article/yemen-cholera-outbreak-nowlargest-and-fastest-record-600000-children-infected-christmas. Last Accessed 2018 Jan 2].

3. WHO. Statement by UNICEF Executive Director, Anthony Lake, WFP Executive Director, David Beasley and WHO Director-General, Dr Tedros Adhanom Ghebreyesus, following their joint visit to Yemen 2017 [Available from: http://www.who.int/en/news-room/detail/26-07-2017-statement-byunicef-executive-director-anthony-lake-wfp-executive-director-david-beasleyand-who-director-general-dr-tedros-adhanom-ghebreyesus-following-theirjoint-visit-to-yemen. Last Accessed 2018 May 8].

4. WHO. Outbreak update - Cholera in Yemen, 25 October 2018 [Available from: http://www.emro.who.int/ar/pandemic-epidemic-diseases/cholera/ outbreak-update-cholera-in-yemen-25-october-2018.html. Last Accessed 2018 Nov 4].

5. WHO. Yemen Cholera Response - Weekly Epidemiological Bulletin 2018 [Available from: http://www.emro.who.int/images/stories/yemen/week_26. pdf?ua=1. Last Accessed 2018 Oct 19].

6. The Lancet. Yemen and cholera: a modern humanity test. Lancet. 2017: 390(10095):626.

7. WHO. Children aged $<5$ years stunted; Data by country 2018 [Available from: http://apps.who.int/gho/data/node.main.CHILDSTUNTED?lang=en. Last Accessed 2018 April 26].

8. WHO/UNICEF Joint Monitoring Programme for Water Supply SaH. Yemen 2018 [Available from: https://washdata.org/data. Last Accessed 2018 Apr 24]

9. Human Rights Watch. Bombing Businesses 2016 [Available from: https:// www.hrw.org/report/2016/07/11/bombing-businesses/saudi-coalitionairstrikes-yemens-civilian-economic-structures. Last Accessed 2018 May 9].

10. Reuters. Saudi-led warplanes hit Yemeni port, aid group sounds alarm 2015 [Available from: https://www.reuters.com/article/us-yemen-security/saudiled-warplanes-hit-yemeni-port-aid-group-sounds-alarm-idUSKCNOQNOHX 20150818. Last Accessed 2018 Jan 2].

11. CNN. Trump calls on Saudi Arabia to end Yemen blockade 2017 [Available from: http://edition.cnn.com/2017/12/06/politics/trump-saudi-blockadeyemen/index.html. Last accessed 2018 May 9].

12. Oxfam. Yemeni people's ability to access food threatened as main supply route to Sanaa targeted by airstrikes 2016 [Available from: https://www. oxfamamerica.org/press/yemeni-peoples-ability-to-access-food-threatenedas-main-supply-route-to-sanaa-targeted-by-airstrikes/. Last Accessed 2018 May 9].

13. Medecins Sans Frontieres. MSF-Supported Hospital Bombed in Northern Yemen 2016 [Available from: https://www.doctorswithoutborders.ca/article/ msf-supported-hospital-bombed-northern-yemen-killing-patients-andinjuring-staff. Accessed 9 May 2018]. 
14. New York Times. Bombing of Doctors Without Borders Hospital in Yemen Kills at Least 152016 [Available from: https://www.nytimes.com/2016/08/16/ world/middleeast/yemen-doctors-without-borders-hospital-bombing.html. Last Accessed 2018 May 8].

15. UNOCHA. Yemen 2018 [Available from: http://www.unocha.org/yemen/ about-ocha-yemen. Last Accessed 2018 Apr 24].

16. World Bank. Pump price for diesel fuel (US\$ per liter) 2018 [Available from: https://data.worldbank.org/indicator/EP.PMP.DESL.CD. Last accessed 2018 April 24].

17. Oxfam. Two-thirds of people in conflict-hit Yemen without clean water 2015 [Available from: https://www.oxfam.org/en/pressroom/pressreleases/ 2015-05-26/two-thirds-people-conflict-hit-yemen-without-clean-water. Last Accessed 2018 Apr 27]

18. World Bank. Consumer price index $(2010=100) 2018$ [Available from: https://data.worldbank.org/indicator/FP.CPI.TOTL. Last Accessed 2018 Apr 24].

19. Oxfam Yemen: Catastrophic Cholera Crisis 2017 [Available from: https:// www.oxfam.org/sites/www.oxfam.org/files/file_attachments/bn-yemencholera-160817-en.pdf. Last Accessed 2018 Apr 27].

20. Kennedy J, Harmer A, McCoy D. The political determinants of the cholera outbreak in Yemen. Lancet Glob Health. 2017;5(10):e970-e1.

21. Dureab F, Shabib K, Albrecht J. The association of cholera outbreak with conflict-related factors in Yemen. Trop Med Int Health. 2017; 22(Supplement 1):53.

22. The Lancet Gastroenterology \& Hepatology. Health catastrophe: the toll of cholera in Yemen (Editorial). 2017;2(9):619.

23. Burki T. Yemen's neglected health and humanitarian crisis. Lancet. 2016; 387(10020):734-5.

24. Medecins Sans Frontieres. Yemen: "The cholera catastrophe is a warning call in a neglected crisis." 2017 [Available from: https://www.msf.org.za/storiesnews/staff-patient-stories/yemen-cholera-catastrophe-warning-call-neglectedcrisis. Last Accessed 2018 Apr 27].

25. The Lancet. Protecting health in Yemen. Lancet. 2016;388(10054):1852.

26. Zarocostas J. Cholera outbreak in Haiti-from 2010 to today. Lancet. 2017; 389(10086):2274-5.

27. Anh DD, Lopez AL, Thiem VD, Grahek SL, Duong TN, Park JK, et al. Use of oral cholera vaccines in an outbreak in Vietnam: a case control study. PLoS Negl Trop Dis. 2011;5(1):e1006.

28. Centers for Disease Control \& Prevention (CDC). Cholera epidemic after increased civil conflict -- Monrovia, Liberia, June-September 2003. MMWR: Morbidity \& Mortality Weekly Report. 2003;52(45):1093-5.

29. Lam E, Al-Tamimi W, Russell SP, Butt MO, Blanton C, Musani AS, et al. Oral cholera vaccine coverage during an outbreak and humanitarian crisis, Iraq 2015. Emerg Infect Dis. 2017;23(1):38-45.

30. International Coordinating Group. International Coordinating Group oral cholera vaccine annual meeting report 20152015 [Available from: http:// www.who.int/cholera/vaccines/Final_OCV_ICG_Meeting_report_June15. pdf?ua=1:. Last accessed 2018 April 27].

31. WHO. Health Cluster Bulletin August 20172017 [Available from: http://www emro.who.int/images/stories/yemen/Health_Cluster_Bulletin_August_2017. pdf?ua=1. Last Accessed 2018 Jan 2].

32. WHO, Yemen WASH Cluster, Yemen Health Cluster. Joint Cholera Response Plan Yemen July 20172017 [Available from: https://reliefweb.int/report/ yemen/joint-cholera-response-plan-yemen-july-2017. Last Accessed 2018 Apr 27].

33. WHO. Yemen Humanitarian Response Plan 20172017 [Available from: http://www.who.int/emergencies/response-plans/2017/yemen/en/. Last Accessed 2018 Apr 27]

34. WHO. WHO's Response to Cholera in Yemen 2017 [Available from: www emro.who.int/yem/yemeninfocus/situation-reports.html. Last Accessed 2018 Jan 2].

35. UNICEF. UNICEF's response to the Cholera Outbreak in Yemen: Terms of Reference for a Real-Time Evaluation 2017 [Available from: www.unicef.org/ evaluation/files/RTE_for_the_Yemen_Cholera_Response_Final_TOR_16_Oct_ 2017.pdf. Last Accessed 2018 Jan 2].

36. UNICEF. Emergency Coordination and the WASH Cluster Initiative 2018 [Available from: https://www.unicef.org/wash/index_43104.html. Last Accessed 2018 Oct 21]

37. International Rescue Committee. Yemen 2017 [Available from: www.rescue. org/country/yemen\#how-does-the-irc-help-in-yemen. Last Accessed 2018 Jan 2].
38. Ahmadzai TK, Maburutse Z, Miller L, Ratnayake R. Protecting public health in Yemen. Lancet. 2016:388(10061):2739.

39. International Committee of the Red Cross. Yemen: War in the time of cholera 2017 [Available from: www.icrc.org/en/document/yemen-war-timecholera. Last Accessed 2018 Jan 2].

40. Medecins Sans Frontieres. Yemen: MSF reduces its cholera response as admissions drop 2017 [Available from: www.msf.org/en/article/yemenmsf-reduces-its-cholera-response-admissions-drop. Last Accessed 2018 January 2].

41. Medecins Sans Frontieres. Yemen: cholera continues to spread 2017 [Available from: www.msf.org/en/article/yemen-cholera-continues-spread. Last Accessed 2018 Jan 2].

42. WHO. Health system in Yemen close to collapse. Bull World Health Organ. 2015;93(10):670-1.

43. Alamodi AA, Eshaq AM, Fothan AM, Bakather AM, Obad AS. Tackling preventable diseases in Yemen. Lancet. 2015;386(10010):2251-2.

44. UNOCHA. Yemen: Donors Pledge \$2 Billion to Scale Up Aid Delivery 2018 [OAvailable from: http://www.unocha.org/sites/unocha/files/Pledge\%20 sheet\%20-\%20Yemen\%20Pledging\%20Event.pdf. Last Accessed 2018 Apr 26].

45. Al Jazeera. Military Action in Yemen: Who's for, who's against? 2017 [Available from: http://www.aljazeera.com/indepth/interactive/2015/03/ military-action-yemen-150326143748798.html. Last Accessed 2018 Apr 26].

46. France 24. Saudi-led strikes target Houthi positions on border with Yemen 2015 [Available from: http://www.france24.com/en/20150506-yemen-saudiled-strikes-target-houthi-rebel-positions-border. Last Accessed 2018 May 8].

47. Reuters. Saudi-led coalition probably used cluster bombs in Yemen: HRW 2015 [Available from: https://www.reuters.com/article/us-yemen-securitycluster-bombs/saudi-led-coalition-probably-used-cluster-bombs-in-yemenhrw-idUSKBNONO09J20150503. Last Accessed 2018 May 8].

48. New York Times. Saudi Arabia Leads Air Assault in Yemen 2015 [Available from: https://www.nytimes.com/2015/03/26/world/middleeast/al-anad-airbase-houthis-yemen.html. Last Accessed 2018 May 8].

49. Business Insider UK. Here are the members of the Saudi-led coalition in Yemen and what they're contributing 2015 [Available from: http://uk. businessinsider.com/members-of-saudi-led-coalition-in-yemen-theircontributions-2015-3? $r=U S \& \mathbb{R}=$ T. Last Accessed 2018 May 8].

50. Al Jazeera. Saudi and Arab allies bomb Houthi positions in Yemen 2015 [Available from: https://www.aljazeera.com/news/middleeast/2015/03/saudiambassador-announces-military-operation-yemen-150325234138956.html. Last Accessed 2018 May 8].

51. WHO. Outbreak update - cholera in Yemen, 19 December 20172017 [Available from: http://www.emro.who.int/pandemic-epidemic-diseases/ cholera/outbreak-update-cholera-in-yemen-19-december-2017.html. Last Accessed 2018 Oct 24].

52. WHO. Dashboard: International Coordinating Group (ICG) on Vaccine Provision on cholera 2017 [Available from: http://www.who.int/csr/disease/ icg/cholera-dashboard/en/. Last Accessed 2018 Nov 4].

53. Qadri F, Islam T, Clemens JD. Cholera in Yemen - an old foe rearing its ugly head. N Engl J Med. 2017;377(21):2005-7.

54. Reliefweb. Oral Cholera Vaccination Campaign in Yemen Falls Short 2018 [Available from: https://reliefweb.int/report/yemen/oral-cholera-vaccinationcampaign-yemen-falls-short. Last Accessed 2018 Oct 24].

55. UN News. Yemen: as cholera surges again, UN and partners double down on vaccination efforts 2018 [Available from: https://news.un.org/en/story/ 2018/10/1022062. Last Accessed 2018 Oct 24].

56. Bi Q, Ferreras E, Pezzoli L, Legros D, Ivers LC, Date K, et al. Protection against cholera from killed whole-cell oral cholera vaccines: a systematic review and meta-analysis. Lancet Infect Dis. 2017;17(10):1080-8.

57. Clemens JD, Nair GB, Ahmed T, Qadri F, Holmgren J. Cholera. Lancet. 2017; 390(10101):1539-49.

58. WHO. Deployments from the oral cholera vaccine stockpile, 2013-2017. Wkly Epidemiol Rec. 2017;92(32):437-42.

59. Desai SN, Pezzoli L, Alberti KP, Martin S, Costa A, Perea W, et al. Achievements and challenges for the use of killed oral cholera vaccines in the global stockpile era. Hum Vaccin Immunother. 2017; 13(3):579-87

60. Parker LA, Rumunu J, Jamet C, Kenyi Y, Lino RL, Wamala JF, et al. Neighborhood-targeted and case-triggered use of a single dose of oral cholera vaccine in an urban setting: feasibility and vaccine coverage. PLoS Negl Trop Dis. 2017;11(6):e0005652. 
61. Teoh SL, Kotirum S, Hutubessy RCW, Chaiyakunapruk N. Global economic evaluation of oral cholera vaccine: a systematic review. Hum Vaccin Immunother. 2018;14(2):420-9.

62. Ilboudo PG, Le Gargasson JB. Delivery cost analysis of a reactive mass cholera vaccination campaign: a case study of Shanchol vaccine use in Lake Chilwa. Malawi BMC Infect Dis. 2017;17(1):779.

63. Poncin M, Zulu G, Voute C, Ferreras E, Muleya CM, Malama K, et al. Implementation research: reactive mass vaccination with single-dose oral cholera vaccine. Zambia Bull World Health Organ. 2018;96(2):86-93.

64. Routh JA, Sreenivasan N, Adhikari BB, Andrecy LL, Bernateau M, Abimbola T, et al. Cost Evaluation of a Government-Conducted Oral Cholera Vaccination Campaign-Haiti, 2013. Am J Tropical Med and hygiene. 2017;97(4_Suppl):37-42.

65. Teshome S, Desai S, Kim JH, Belay D, Mogasale V. Feasibility and costs of a targeted cholera vaccination campaign in Ethiopia. Hum Vaccin Immunother. 2018:1-7.

66. Human Rights Watch. Yemen - Events of 20162017 [Available from: www.hrw. org/world-report/2017/country-chapters/yemen. Last Accessed 2018 Jan 2].

67. Task Force on Population Movement. Yemen: 17th Report — August 2018 2018 [Available from: https://displacement.iom.int/reports/yemen---tfpmreport-17-august-2018. Last Accessed 2018 Oct 24].

68. Zaidi A. Make plans to eliminate cholera outbreaks. Nature. 2017:550(7674):9.

69. Parker LA, Rumunu J, Jamet C, Kenyi Y, Lino RL, Wamala JF, et al. Adapting to the global shortage of cholera vaccines: targeted single dose cholera vaccine in response to an outbreak in South Sudan. Lancet Infect Dis. 2017; 17(4):e123-e7.

70. Qadri F, Wierzba TF, Ali M, Chowdhury F, Khan Al, Saha A, et al. Efficacy of a single-dose, inactivated Oral cholera vaccine in Bangladesh. N Engl J Med. 2016;374(18):1723-32.

71. Azman AS, Parker LA, Rumunu J, Tadesse F, Grandesso F, Deng LL, et al. Effectiveness of one dose of oral cholera vaccine in response to an outbreak: a case-cohort study. Lancet Glob Health. 2016;4(11):e856-e63.

72. Rebaudet S, Gaudart J, Piarroux R. Vaccination against cholera in juba. Lancet Infect Dis. 2017;17(5):479-80.

73. Ciglenecki I, Azman AS, Rumunu J, Cabrol J-C, Luquero FJ. Vaccination against cholera in juba - Authors' reply. Lancet Infect Dis. 2017;17(5):480-1.

74. Pastor M, Pedraz JL, Esquisabel A. The state-of-the-art of approved and under-development cholera vaccines. Vaccine. 2013;31(38):4069-78.

75. The Sphere Project. The Sphere Handbook 2011 [Available from: www. sphereproject.org. Last Accessed 2018 Jan 2].

76. The Sphere Project. The Sphere Handbook Draft 22017 [Available from: http://www.sphereproject.org/handbook/revision-sphere-handbook/. Last Accessed 2018 Oct 27]

77. Global Task Force on Cholera Control. Ending Cholera: A Global Roadmap to 2030. p. 2017

78. WHO. Vaccination in Acute Humanitarian Emergencies: A Framework for Decision Making 2017 [Available from: http://apps.who.int/iris/bitstream/ handle/10665/255575/WHO-IVB-17.03-eng.pdf?sequence=1. Last Accessed 2018 Apr 26].

79. WHO. Cholera vaccines: WHO position paper - August 20172017 [Available from: http://apps.who.int/iris/bitstream/handle/10665/258763/WER9234.pdf; jsessionid=93D217898B13F0B351877EDAA1E45E5F?sequence=1. Last Accessed 2018 Apr 26]

80. WHO. Cholera vaccination campaign begins in north-eastern Nigeria 2017 [Available from: http://www.afro.who.int/news/cholera-vaccinationcampaign-begins-north-eastern-nigeria. Last Accessed 2018 Mar 4].

81. United Nations. UN agencies launch cholera immunization campaign for Rohingya refugees in Bangladesh 2017 [Available from: https://news.un. org/en/story/2017/10/568162-un-agencies-launch-cholera-immunizationcampaign-rohingya-refugees-bangladesh\#.WkksF9-nHn0. Last Accessed 2018 Mar 4].

82. Rull M, Masson S, Peyraud N, Simonelli M, Ventura A, Dorion C, et al. The new WHO decision-making framework on vaccine use in acute humanitarian emergencies: MSF experience in Minkaman. South Sudan Confl Health. 2018;12:11.

83. Abubakar A, Azman AS, Rumunu J, Ciglenecki I, Helderman T, West H, et al. The first use of the global Oral cholera vaccine emergency stockpile: lessons from South Sudan. PLoS Med. 2015;12(11):e1001901.

84. Schwerdtle P, Onekon CK, Recoche K. A quantitative systematic review and meta-analysis of the effectiveness of Oral cholera vaccine as a reactive measure in cholera outbreaks. Prehosp Disaster Med. 2018:33(1):2-6.

Ready to submit your research? Choose BMC and benefit from:

- fast, convenient online submission

- thorough peer review by experienced researchers in your field

- rapid publication on acceptance

- support for research data, including large and complex data types

- gold Open Access which fosters wider collaboration and increased citations

- maximum visibility for your research: over $100 \mathrm{M}$ website views per year

At BMC, research is always in progress.

Learn more biomedcentral.com/submissions 